\title{
BIM: Relatos de aplicação no ensino de arquitetura
}

\author{
BIM: Application reports in the teaching of architecture
}

- Vivian Delatorre

UFSC/POSARQ /UNOCHAPECÓ, Brazil

viviandelatorre.arq@gmail.com

Juliano Miotto

UFSC/POSARQ/ UNOCHAPECÓ, Brazil

miotto.arquiteto@gmail.com

- Alice Theresinha Cybis Pereira

UFSC/POSARQ, Brazil

alice.cybis.pereira@ufsc.br

\begin{abstract}
This paper presents the first application reports of BIM in the Architecture and Urbanism course at UNOCHAPECÓ University, Brazil. This course, which began inserting BIM in its curriculum in 2014, shows considerations on the implementation of BIM in a discipline of architectural design. In addition, this paper aims to understand the students' viewpoint regarding the insertion of BIM through a questionnaire. As a result, it presents the reflections of this experience in teaching BIM. This study expects to generate contributions to new practices in the teaching of architecture and urbanism and to advance the knowledge about BIM.
\end{abstract}

Keywords: BIM, Teaching, Architecture

\section{Introdução}

Com o surgimento do BIM transformações significativas ocorrem no processo de projeto e em todas as fases de planejamento e construção do edifício. Além da inserção de uma tecnologia, o mesmo refere-se a um conjunto integrado de políticas e processos, que requerem práticas colaborativas, interdisciplinares e integradas, desde a fase de concepção. (Eastman et al., 2014; Succar, 2008).

O BIM vem sendo aplicado nas escolas de Arquitetura e Engenharia a nível internacional e nacional, mas pesquisas tem mostrado que o Brasil tem muito a avançar se comparado ao quadro internacional (Barison e Santos, 2011; Ruschel et al., 2013; Taylor, Hein; 2008). Acredita-se que a melhora deste quadro no Brasil, depende de um maior movimento das escolas de Arquitetura e Engenharia implementarem o BIM no ensino, gerando experiências que possam ser compartilhadas.

Este trabalho tem como objetivo apresentar os primeiros relatos da aplicação do BIM no curso de Arquitetura e Urbanismo da Universidade Comunitária da Região de Chapecó, iniciado em 2014. Assim como, expor a visão do aluno neste processo e exemplificar a inserção do BIM em disciplina de projeto arquitetônico, referente ao primeiro semestre de 2015 , e a sua relação com as demais disciplinas projetivas e de representação gráfica.

Como resultado, se tem apontamentos e reflexões que procedem desta experiência, por meio da aplicação prática e considerando a visão do aluno. E espera-se que o mesmo possa gerar contribuições para novas experiências no intuito de avançar o conhecimento sobre o BIM no ensino de arquitetura e urbanismo.

\section{Processo de Projeto X BIM}

Uma grande parte das literaturas que tratam sobre metodologia de projeto, conforme estudos mostrados por Kowaltowski (2011), abordam exatamente as fases do processo de projeto descritas por Lawson (2011), envolvendo os conceitos de Análise, Síntese e Avaliação.

Estes conceitos são apresentados por Kowaltowski (2011), que define a análise como uma fase de identificação dos principais elementos que compõem o problema de projeto, a síntese refere-se à busca de soluções, as quais podem ser parciais ou globais e a avaliação detecta as possíveis inconsistências do projeto antes da construção. A Representação compreende a comunicação e os instrumentos de representação.

A Norma brasileira que trata sobe a elaboração de projetos de edificações - Arquitetura (NBR 13.532), define as seguintes etapas de desenvolvimento do projeto arquitetônico:

a) Levantamento de dados para arquitetura;

b) Programa de necessidades de arquitetura;

c) Estudo de viabilidade de arquitetura;

d) Estudo preliminar de arquitetura; 
e) Anteprojeto de arquitetura ou de pré-execução;

f) Projeto legal de arquitetura;

g) Projeto básico de arquitetura;

h) Projeto para execução de arquitetura.

Ainda sobre as fases referentes ao processo são definidas por Silva (2006), envolvendo: o programa, como sendo síntese do problema, a proposta de solução, iniciada com partido arquitetônico; o desenvolvimento da forma a ser construída; a descrição da forma e as prescrições para a execução.

Para Neves (1998), o Partido Arquitetônico é definido como a ideia preliminar do edifício a ser concebido e ressalta que o projetista deve criar a habilidade de imaginar o edifício de forma tridimensional, mesmo que esteja trabalhando em planos bidimensionais. Três etapas que contemplam o Partido Arquitetônico são descritas por Neves (1998):

- $1^{\text {a }}$ etapa: Coletar, armazenar e analisar informações. Dados teóricos, parâmetros, variáveis de natureza conceitual e os dados de natureza físico-ambiental (dados que correspondem ao terreno);

- $2^{\circ}$ etapa: Desencadear o processo de síntese e obter a ideia da solução arquitetônica e formulação da ideia básica do edifício (Partido Arquitetônico)

- $3^{\text {a }}$ etapa: Evolução da ideia com objetivo de chegar a fase de conclusão do projeto (Desenvolvimento da ideia gerada pelo partido Arquitetônico);

O processo de projeto na Arquitetura sofreu mudanças significativas, principalmente nos últimos anos, com a rápida evolução das tecnologias digitais. Os projetos, como dos arquitetos Frank O. Gehry, Norman Foster, Zaha Hadid, são exemplos de como a tecnologia gerou mudanças na forma de projetar e vem demonstrando o impacto, que os recursos computacionais têm sobre o edifício, principalmente relacionados aos aspectos formais, incluindo análises e simulações.

Para Eastman et al. (2014), a utilização de ferramentas paramétricas, em específico o BIM, além de melhorias no processo de projeto também oferece uma gama de informações em todas as fases do desenvolvimento do projeto. E segundo o autor muitas melhorias ainda estão por vir.

Eastman et al. (2014) considera três pontos de aplicação de ferramentasBIMnoprocessodeprojeto.Oprimeirorelacionado ao projeto conceitual, ou seja, parte criativa do projeto. $O$ segundo relacionado as análises, simulações e avaliações, em conjunto com o trabalho integrado e colaborativo e o último aspecto está relacionado as informações geradas por meio do modelo, como também procedimentos não padronizados que resultam em projeto para fabricação.

Integrado a estas etapas de projeto, o American Institute of Architecture (AIA), define as classes de LOD (Level of Development), que, refere-se ao nível de desenvolvimento em BIM, que descreve o mínimo dimensional, espacial, dados quantitativos, qualitativos e outros elementos incluídos em um modelo para apoiar os usos autorizados associados ao nível de detalhes.

Os LOD's referem-se as seguintes etapas:
- LOD 100: fase de estudo preliminar, a geometria do modelo pode ser considerada conceitual.

- LOD 200: fase de anteprojeto, ou projeto em desenvolvimento, cuja geometria é aproximada,

- LOD 300: fase de projeto executivo, necessita de uma geometria mais precisa, envolvendo detalhamentos e toda a documentação,

- LOD 400: a fase de preparação da obra, construção e montagem, envolvendo as etapas de fabricação e construção

-LOD 500: a fase de pós ocupação, o modelo tridimensional é utilizado para operação e manutenção.

Este cenário mostra uma séria de conceitos e metodologias que surgem com oBIM, gerando novos processos queenvolvem práticas colaborativas, multidisciplinares e integradas desde a fase de concepção. Estas práticas incluem simulações, análises, levantamento de custos e a comunicação dos profissionais em todas as fases e etapas do projeto e construção.

Observa-se que as discussões sobre o BIM estão mais voltadas as práticas de coordenação, compatibilização e gerenciamento de projeto e pouco se tem discutido o processo de geração da forma, relacionado as fases de concepção do projeto em BIM.

Eastman et al. (2014), afirma que alguns novos métodos em projeto arquitetônico digital passaram a usar o BIM, não apenas como meio de armazenar e gerenciar conhecimentos do edifício, mas também contribuindo para a transformação e a geração de novas soluções de projeto.

\section{Metodologia}

Os procedimentos metodológicos adotados neste trabalho são baseados em:

Revisão Sistemática de Literatura sem meta-análise e Revisão integrativa de Literatura (panorama do BIM no ensino de arquitetura e urbanismo e relatos de práticas e experiências). Breve contextualização do processo de projeto e BIM.

Elaboração de questionário composto por questões fechadas, porém aberto para comentários, sobre a inserção do BIM na matriz atual do curso de Arquitetura e Urbanismo da Unochapecó.

O questionário foi aplicado à 81 alunos, da primeira à terceira fase desta matriz e os alunos expressaram o grau de concordância e discordância (escala Likert) sobre as questões a eles apresentadas. $\mathrm{O}$ objetivo do mesmo foi de conhecer a visão dos estudantes que estão inseridos neste processo. Uma breve análise e discussão destes resultados são apresentados.

Contextualização da introdução do BIM na matriz curricular do urso de Arquitetura e Urbanismo da Unochapecó. E por fim, apresentação da estruturação proposta de inserção do BIM em uma disciplina de projeto arquitetônico e a integração com as demais disciplinas com base em Delatorre (2014). Assim como a apresentação da experiência, do semestre 2015.1, no intuito de exemplificar. 


\section{Análise do questionário}

Para a análise e intepretação dos dados coletados com base no questionário aplicado aos estudantes, gera-se um gráfico (Figura 01) apresentando as respostas das perguntas fechadas e uma breve interpretação dos comentários dos estudantes.

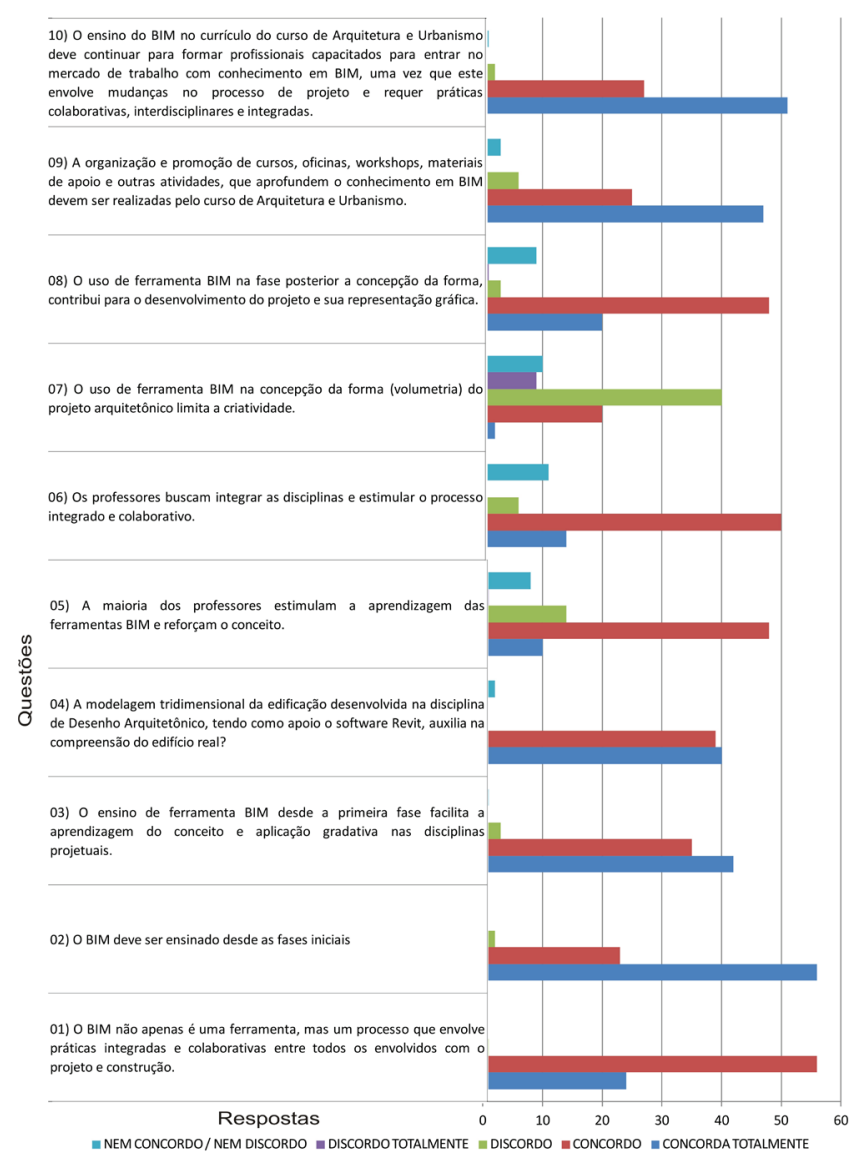

Figura 1: Gráfico com os resultados do questionário, Autores, 2015.

Os alunos conseguem compreender o BIM não apenas como ferramenta, mas também como um processo que envolve práticas colaborativas e integradas. A maior parte dos alunos concordam com o ensino de ferramentas BIM, desde as fases iniciais, com aplicação gradativa nas disciplinas projetuais e que a modelagem tridimensional auxilia na compreensão do edifício projetado. Isso demonstra que embora não se tenha uma imersão de uma experimentação mais intensa dos conceitos e ferramentas BIM, estes conceitos vêm sendo reforçados nas disciplinas.

Quanto ao estímulo do uso das ferramentas BIM por parte dos professores os alunos respondem de forma positiva, mas acham importante que todos os professores dominem o básico das ferramentas para que possam auxiliá-los nas disciplinas projetivas.

Mas quando abordado sobre a integração das disciplinas e estímulo ao processo integrado e colaborativo o grau de concordância foi menor. Isso reforça a retomada da discussão da importância do domínio ou não das ferramentas BIM, por parte dos professores das linhas projetivas. Assim como estudar alternativas para uma interdisciplinaridade mais efetiva, para que as integrações realmente aconteçam.

Em relação ao uso de ferramenta BIM na concepção da forma (volumetria) ser um limitante no processo criativo, mais da metade dos alunos discordam com a afirmativa. Mesmo assim, acrescentam que gostariam de ter mais aulas de

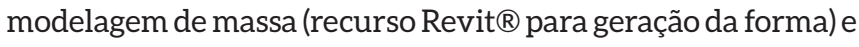
outros abordam o software SketchUP $®$ como uma ferramenta mais interativa para esta etapa. Nesse sentido, percebe-se que os aspectos de concepção da forma em softwares BIM, ainda podem ser explorados.

Já em relação a aplicação nas demais etapas do projeto e representação gráfica, os alunos em sua maioria concordam que a ferramenta contribui, mas relatam a falta de simbologias adequadas a norma brasileira. Além disso, acreditam ser importante a organização e promoção de cursos, oficinas, workshops e materiais de apoio que auxiliem e aprofundem o conhecimento em BIM.

E por fim os alunos apontam como importante o ensino do BIM no currículo de Arquitetura e que esta prática deve ser continuada. Alguns alunos ressaltaram que a maior parte do mercado de trabalho ainda não utiliza ferramenta BIM, o que dificulta a inserção em estágios. Este pode ser um dos desafios da adoção do BIM no ensino, que se refere a preparar profissionais para trabalharem com esse novo processo que requer práticas integradas e colaborativas, modificando o cenário atual.

Considera-se relevante conhecer a visão do aluno por estar inserido neste processo, uma vez que já se teve a opinião parcial dos professores sobre a inserção do BIM na construção da atual matriz, apresentado por Delatorre (2014). Ainda, entende-se que é importante acompanhar esse processo, buscando compreender os diferentes olhares tanto dos docentes quanto dos discentes, para que se possa fazer os ajustes necessários.

\section{Contextualização}

A matriz do curso de Arquitetura e Urbanismo da Universidade da Região de Chapecó (UNOCHAPECÓ) foi adotado no primeiro semestre de 2014 , atualmente está na $4^{a}$ fase do curso. A construção da matriz foi pautada na inserção de novas tecnologias entre elas o BIM. Optou-se por introduzilo dentro das disciplinas e não uma disciplina específica.

O curso de Arquitetura e Urbanismo da Universidade Comunitária da Região de Chapecó discutiu amplamente esta matriz em 2013 e ofereceu treinamento para os professores em software BIM no $1^{\circ}$ semestre de 2014 e $1^{\circ}$ semestre de 2015. Mas por se tratar de uma instituição comunitária, existe uma maior rotatividade dos professores, o que pode resultar falhas no processo, até que se integre estes novos professores nestas discussões. 
Na primeira fase do curso, os alunos já são inseridos no uso de ferramenta BIM (Revit $\circledast$ ), na disciplina de Desenho Arquitetônico I, o qual é ensinado representação gráfica a partir da modelagem tridimensional, estimulando o entendimento das representações bidimensionais.

Esta experiência do uso de ferramenta digital nas primeiras fases para representação técnica do projeto já havia sido discutido e aceito pelo corpo docente, na matriz anterior. Já se tem uma metodologia que demonstrou não haver perda no processo de ensino-aprendizagem. No entanto, existem disciplinas específicas para expressão gráfica manual, ou seja, acredita-se que mesmo com o uso de ferramenta BIM, os croquis devem ser estimulados.

Para exemplificar o estudo e a metodologia aplicada apresenta-se as considerações sobre a estruturação da proposta como também se relata a inserção do BIM em uma disciplina de Projeto Arquitetônico e a sua integração com as demais disciplinas, com uma breve contextualização do processo.

\section{Considerações sobre estruturação da proposta}

As considerações sobre a proposta foram estruturadas com base em diversos relatos de experiências nacionais e internacionais de aplicação do BIM no ensino (Taylor, Hein, 2008; Denzer e Hedges,2008; Sacks e Barak, 2010; Barison e Santos, 2011, Wong et al. , 2011; Kiviniemi, 2013, Barham et al. , 2013, Ruschel, Andrade e Morais, 2013).

A disciplina de Projeto Arquitetônico: Residência Unifamiliar tem o foco no desenvolvimento de uma residência em diferentes níveis, com o mínimo de impacto no terreno, explorando as questões formais adequadas à função e ao prélançamento da estrutura.

As disciplinas de Arquitetura de Interiores I, Fabricação Digital e Prototipagem Rápida, Experimentação da Concepção Estrutural e Arquitetura Paisagística podem trabalhar em conjunto com a Disciplina de Projeto Arquitetônico: Residência Unifamiliar (Figura 02).

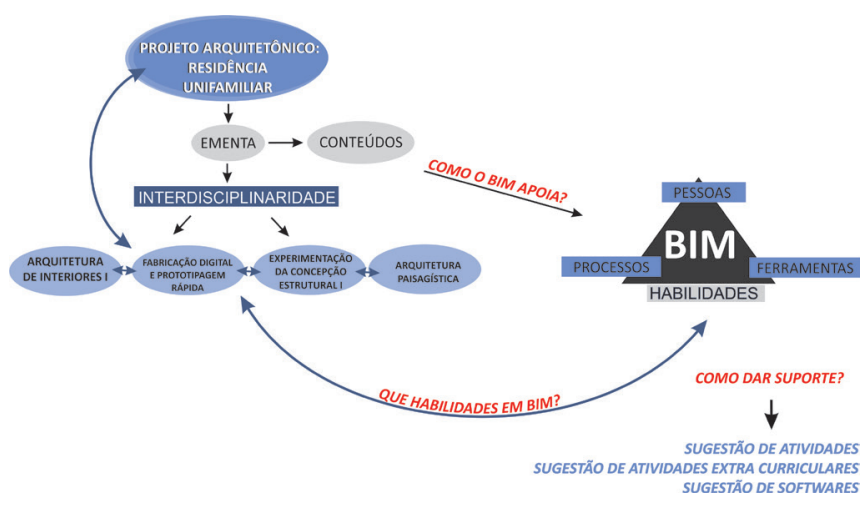

Figura 2: Esquema integração Projeto Arquitetônico Residência Unifamiliar, Delatorre, 2014.

Acredita-se que nessa fase os alunos já possuirão embasamento em modelagem BIM, adquiridos nas disciplinas de Desenho Arquitetônico I ( $1^{\circ}$ fase), Desenho Arquitetônico II ( $2^{\circ}$ fase) para explorar e experimentar diferentes tipologias e formas associadas ao terreno, ao entorno, aos desníveis e considerando os princípios de conforto. Permite-se que, ainda nas fases de concepção com auxílio de modelo tridimensional LOD 100, o aluno defenda as soluções adotadas testando e analisando o modelo.

Integrada à disciplina Fabricação Digital e Prototipagem Rápida, pode-se trabalhar também com softwares BIM, materializando os modelos gerados pelos alunos ainda na fase de concepção e auxiliando no processo de projeto. É possível que nessa etapa os alunos trabalhem com a interoperabilidade, pois, dependendo do tipo de fabricação e do equipamento, os arquivos terão diferentes extensões.

A disciplina de Fabricação Digital e Prototipagem Rápida ainda pode apresentar, brevemente, os conceitos de Modelos Generativos, mostrando outras formas de concepção, instigando os alunos para diferentes métodos, uma vez que a matriz não possuiu disciplina específica. $O$ conteúdo pode ser aprofundado por meio de cursos, oficinas e/ou workshops. Isso, por entender que os modelos podem se integrar futuramente ao BIM, conforme apresentado por Oxman (2006) e definido pela autora como modelo composto se integrado a outras soluções.

Ainda nas fases de concepção da forma a disciplina de Experimentação da Concepção Estrutural, pode fornecer o embasamento necessário aos alunos, quanto à importância da integração arquitetura e estrutura nas fases iniciais. $O$ professor pode orientá-los a partir do modelo LOD 100, para que entendam, por exemplo, alinhamento de paredes, dimensões de balaços permitidos para os diferentes sistemas estruturais, pré-lançamento dos pilares, entre outros. As noções contribuem para o posterior lançamento da estrutura no projeto.

Tendo em vista que a residência é de dois pavimentos, o uso do modelo tridimensional auxilia na visualização do lançamento estrutural por meio do software, que trabalha com pavimento sobre pavimento. A disciplina de Experimentação da Concepção Estrutural pode tirar partido do BIM, para os alunos compreenderem e visualizarem os elementos estruturais de forma tridimensional e bidimensional, bem como poderá aplicar a prototipagem rápida.

É importante abordar os conceitos de colaboração e integração, mesmo que estes ainda não sejam aplicados. Embora o projeto ainda é trabalhado de forma individual, é necessário que entendam a importância do trabalho colaborativo e interdisciplinar já nas fases de concepção e que se estendem por toda a etapa de desenvolvimento do projeto e construção.

Por entender que no projeto haverá uma primeira exigência em relaçãoà integraçãoentrearquitetura eestrutura, é possível que os alunos sintam o impacto em relação a buscar soluções que atendem a vários condicionantes, como: forma, função, estrutura, mínimo de impacto no terreno, noções conforto ambiental e previsão de sistemas complementares. 
A disciplina de Arquitetura de Interiores pode trabalhar com o mesmo projeto que a disciplina de Projeto Arquitetônico, integrando os conteúdos e apoiando o aluno na compreensão do espaço externo e interno em um mesmo exercício. A disciplina de Arquitetura Paisagística pode fazer o mesmo e tirar partido dos conhecimentos sobre a modelagem.

No modelo desenvolvido para a disciplina de projeto, os alunos podem aplicar os conhecimentos da disciplina de Desenho Arquitetônico II, o qual teve ênfase na modelagem, buscando visualizar e compreender o espaço interno. E também testar cores e texturas, modelando o próprio mobiliário, associado às exigências do mercado, buscando materiais existentes na indústria, relacionando a concepção, fabricação e montagem.

Ainda a disciplina de interiores pode se integrar à disciplina de Fabricação Digital e Prototipagem Rápida, para desenvolvimento de protótipo, por exemplo, de um mobiliário, desenvolvido em grupos e trabalhando de forma colaborativa.

Para o desenvolvimento do anteprojeto, a disciplina de Projeto Arquitetônico pode exigir um nível de modelagem LOD 200, a partir da massa conceitual desenvolvida em LOD 100, também detalhamentos em LOD 300. Assim como exigir detalhamentos específicos para cada projeto, associados a um trabalho de pesquisa, em que os alunos podem modelar edetalhar os desenhos bidimensionais e compartilhar esta experiência.

Sugestão de Atividades Extracurriculares: Oficinas, cursos e/ou workshops sobre Renderização, Modelagem paramétrica, Introdução aos Sistemas Generativos, Fabricação Digital e Prototipagem Rápida e desenvolvimento de material de apoio envolvendo tutoriais das ferramentas utilizadas nas disciplinas;

Sugestão Ferramentas: Software de Modelagem BIM Arquitetura, Softwares de Render e Softwares para planificação de modelos tridimensionais (corte a laser e CNC).

A tabela 01 mostra a relação Pessoa, Processo e Ferramentas, com base na identificação das habilidades requeridas aos alunos na inserção do BIM, na disciplina de Projeto Arquitetônico Unifamiliar.

\begin{tabular}{|l|l|l|}
\hline \multicolumn{1}{|c|}{ Pessoas } & \multicolumn{1}{c|}{ Processo } & \multicolumn{1}{c|}{ Ferramentas } \\
\hline Individual, \\
buscando atividades \\
em grupo & -Pensamento & -Modelagem \\
& tridimensional (Real & tridimensional LOD \\
& X Abstração); & 100 (sólido); \\
& -Integração entre & -Modelagem tridi- \\
& disciplinas; & mensional LOD 200 \\
& -Pensamento & (Anteprojeto) \\
& crítico das soluções & -Modelagem \\
& adotadas; & tridimensional LOD \\
& & 300 (para detalha- \\
& & mentos) \\
& & -Geração de quadros \\
& & de quadro de áreas e \\
& & esquadrias \\
& & -Estudo de Isolação; \\
& & -Interoperabilidade; \\
& & \\
\hline
\end{tabular}

Tabela 1: Quadro de identificação das habilidades, Delatorre, 2014.

\section{Relatos da aplicação do BIM}

A partir das considerações da estruturação da proposta, relata-se a aplicação do BIM na disciplina de Projeto Arquitetônico: Residência Unifamiliar, semestre de 2015.1, bem como a relação com as disciplinas anteriores que incluíram o BIM em seus conteúdos fornecendo o embasamento necessário para o aluno aplicar nas disciplinas projetivas. Assim como, integração com as disciplinas do mesmo semestre.

Nesta fase, os estudantes já cursaram as disciplinas de desenho arquitetônico I, que utiliza o Revit para a representação gráfica do Projeto, incluindo a norma técnica. Também, a disciplina de desenho arquitetônico II, que aprofunda o conteúdo de desenho arquitetônico I. Além disso, incorpora conteúdos relacionados a modelagem paramétrica de objetos, visando a personalização da biblioteca, modelagem de massa conceitual, como auxilio para a fase de concepção da forma arquitetônica e renderização do projeto, visando melhorar a apresentação do mesmo.

A metodologia da disciplina do projeto arquitetônico: Residência Unifamiliar é composta pelas seguintes etapas: definição do perfil da família, análise de referenciais, programa de necessidades, pré-dimensionamento, coleta e análise de dados físicos, ambientais e legislação, elaboração de um conceito para o projeto, definição das diretrizes projetuais e lançamento do partido arquitetônico (Neves, 2008), com base no conceito e nos dados levantados e analisados.

$\mathrm{Na}$ fase de desenvolvimento do partido arquitetônico os alunos em sua maioria utilizaram o Revit ${ }^{\circledR}$ (Figura 03). Em um primeiro momento, os alunos modelam o terreno e entorno antes de iniciar os estudos volumétricos, isto porque um dos requisitos da disciplina é o mínimo de impacto no terreno e a compreensão dos desníveis.

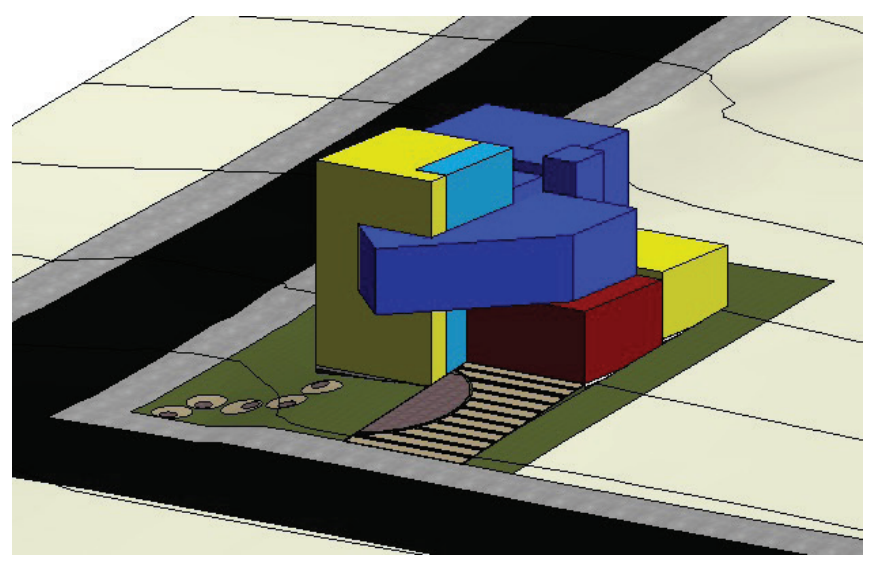

Figura 3: Estudo volumétrico do aluno da $3^{\mathrm{a}}$ fase (Nalin, 2015), setorização da Residência unifamiliar, software Revit®

Nos estudos volumétricos os estudantes geram diferentes tipologias, relacionando com o conceito e considerando os aspectos de pré-dimensionamento, legislação, aspectos 
físicos e ambientais. Na fase do partido arquitetônico, estes estudos volumétricos foram gerados de diferentes formas pelos estudantes tais como: modelagem de massa conceitual do Revit ${ }^{\circledR}$, pela maior liberdade de manipulação da forma. Os estudantes que não dominavam a ferramenta de massa, optaram por utilizar as ferramentas básicas do Revit®. Alguns estudantes preferiram o software Sketchup $₫$ por entenderem ser mais intuitivo e uma minoria optou por iniciar por croquis a mão livre.

Após a definição da volumetria os alunos desenvolveram a maquete física, onde a disciplina de Fabricação Digital auxiliou no desenvolvimento do terreno utilizando o corte a laser. Neste semestre ainda não foi possível desenvolver toda a maquete no laboratório de fabricação digital e prototipagem rápida por questões de organização interna do mesmo.

Com o partido arquitetônico desenvolvido, os alunos iniciaram a fase de anteprojeto, apresentando a situação, implantação, as plantas baixas, cortes, fachadas e detalhamentos, como também a resolução formal (figura 04) e estrutural (Figura 05). Nesta etapa todos os alunos utilizaram o software Revit ${ }^{\circ}$, compreendendo as relações e fazendo os ajustes necessários entre forma, função, estrutura, estudo solar, relação do terreno e entorno e previsão de sistemas complementares.

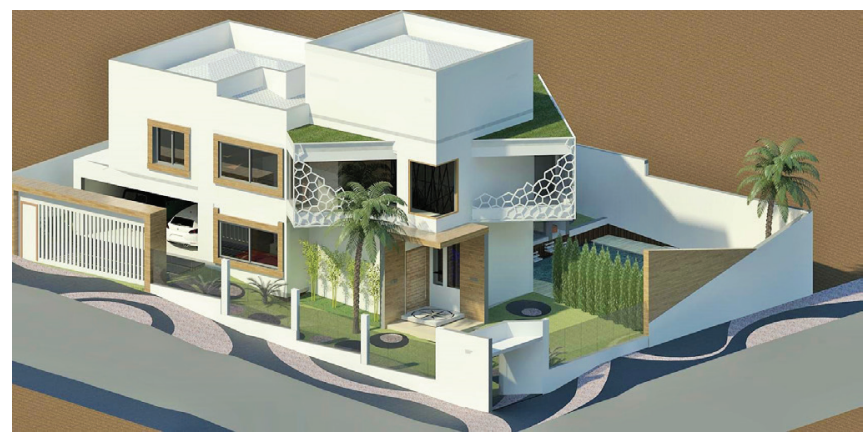

Figura 4: Volumetria final do projeto da residência unifamiliar do aluno da $3^{\text {a }}$ fase (Nalin, 2015), software Revit ${ }^{\circledR}$

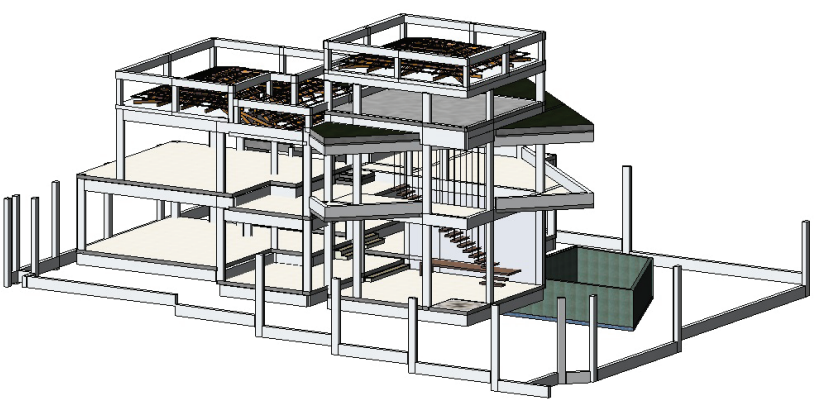

Figura 5: 3D estrutural do projeto da residência unifamiliar do aluno da $3^{\text {a }}$ fase (Nalin, 2015), software Revit ${ }^{\circledR}$

Os alunos que não utilizaram o Revit ${ }^{\circledR}$ desde as etapas iniciais, por problemas de interoperabilidade, refizeram o trabalho no Revit ${ }^{\circledR}$. Ou seja, a forma inicial desenvolvida no software Sketchup ${ }^{\circledR}$, foi refeita no software Revit ${ }^{\circledR}$, após a definição do partido Arquitetônico. Diferente dos alunos que iniciaram no Revit ${ }^{\circledR}$, estes apenas deram continuidade nas etapas, fazendo pequenos ajustes.

A disciplina de arquitetura de interiores e a disciplina de paisagismo trabalharam de forma integrada com a disciplina de projeto arquitetônico, onde os alunos trabalharam com o mesmo projeto durante todo o semestre.

Além disso, na Semana Acadêmica do curso (2015.1), ofereceu lhes três minicursos: Revit ${ }^{\circledR}$ básico, Modelagem de massa conceitual e Renderização, no intuito de dar um maior suporte aos estudantes, como também oportunizar os estudantes da antiga matriz a ter o contato com o software.

Embora não se tenha ainda uma pesquisa aprofundada com os resultados referente a inserção do BIM nesta matriz, empiricamente se faz algumas considerações. $O$ uso de ferramenta BIM nas fases iniciais tem contribuído para o processo de ensino aprendizagem nas disciplinas de projeto, uma vez que o aluno tem a visualização tridimensional.

Está sendo possível ensinar de forma gradativa o conhecimento técnico sobre os elementos modelados, como por exemplo, quando o aluno vai projetar uma parede ele precisa pesquisar sobre a composição desta parede, assim como os padrões de fabricação. Isto estimula a pesquisa e coloca o aluno frente a situações mais reais de elaboração de um projeto arquitetônico, ou seja, deixa de ser uma mera representação do edifício, muito comum no processo de projeto tradicional.

\section{Resultados}

Nesta primeira fase de introdução do BIM percebeuse, assim como afirma Succar (2008), que esta etapa pode parecer que o BIM está baseado apenas em ferramentas. Segundo o autor, faz parte de um processo de transição, uma vez que a tecnologia apoia o processo interdisciplinar, colaborativo e integrado.

Por outro lado, entende-se que o acompanhamento do processo é essencial para que o BIM, não seja visto apenas como a inserção de uma nova ferramenta no currículo de arquitetura, estimulando a colaboração e integração. Porém, uma análise de cada semestre, assim como a revisão do processo pode contribuir para uma inserção mais efetiva.

Observa-se ainda, a necessidade de estudos específicos sobre a fase concepção do projeto, principalmente relacionado aos aspectos formais, utilizando ferramentas BIM, buscando metodologias que estimulem a criatividade e explorem o potencial do software.

A discussão entre os professores quanto ao uso das ferramentas, foi pautada em um apoio e estímulo ao processo (Delatorre, 2014). No entanto, o resultado do questionário aplicado aos alunos detectou-se que estes gostariam que todos os professores da linha projetiva, tivessem um maior domínio da ferramenta. Isto evidencia que novas reflexões sobre este assunto se faz necessária. 
De um modo geral se tem uma boa aceitação por parte dos professores (Delatorre, 2014) e dos alunos quanto a inserção do BIM, na matriz atual. Isto reforça que o BIM é visto como um potencial no ensino, mas o aprimoramento das práticas requer novos experimentos. Deste modo, acredita-se que resultados mais concretos, diagnosticando os potenciais e falhas no processo, serão constatados de forma mais efetiva quando se completar o ciclo.

A maior parte dos alunos estão tendo uma boa adaptação ao processo e o uso das ferramentas BIM, que está incorporada na prática das disciplinas de projeto arquitetônico, assim como em outras disciplinas da linha projetiva e de representação gráfica. Percebese que projetação tridimensional auxilia em uma maior compreensão do aluno, nas soluções projetuais, aproximando de um edifício real.

E por fim, entende-se que o aluno está passando por uma etapa de transição e que o mercado ainda não absorveu estas transformações. Mas acredita-se que a mudança do mercado irá acontecer quando mais escolas introduzirem o BIM em seus currículos. E estes estudantes se tornarem profissionais, tendo como base de sua formação à inserção de novas tecnologias e processos, entre elas o BIM.

Entende-se também que existem diferentes olhares sobre a inserção do BIM no ensino, onde existe divergências sobre ensinar ou não nas fases iniciais. Mas, nesta matriz optou-se por inserir o BIM desde o primeiro semestre, por entender que a inserção gradativa pode contribuir para um maior domínio e aplicação do BIM em todas as fases de projeto. Além disso, já se teve uma experiência anterior em ensinar outro software BIM em disciplinas de Desenho Arquitetônico, da primeira fase do curso (Delatorre; Pereira e Pupo, 2013).

Com essa experiência entendeu-se que não houve perdas no processo de ensino aprendizagem, considerando que a representação gráfica apresentada pelos alunos é adequada. Também, provas de visualização bidimensionais e tridimensionais foram e ainda são aplicadas, para constatar o entendimento do aluno na visualização e representação do projeto e seus elementos, e estas avaliações tiveram resultados positivos.

Assim como, percebe-se uma melhoria na resolução da forma tridimensional do projeto em disciplinas de projeto arquitetônico, como também nas resoluções técnicas auxiliadas diretamente no modelo tridimensional. Entretanto, acreditasse que essas práticas vêm contribuindo para um pensamento projetivo tridimensional e uma maior análise crítica do aluno.

Espera-seque estetrabalho possa gerar novas discussões sobre a aplicação do BIM no ensino e as influências que o mesmo exerce no processo de projeto arquitetônico. Assim como incentivar que outros estudos sejam desenvolvidos, gerando subsídios para criação de novas metodologias. Para novas aplicações no ensino, com base no potencial destas ferramentas, explorando os conceitos de integração e colaboração.

\section{Agradecimentos}

Agradeço aos estudantes e ao curso de Arquitetura e Urbanismo da Unochapecó por contribuírem com o desenvolvimento deste trabalho. Também ao grupo de professores que estão sempre abertos a novas discussões, um grupo integrado que permite que mudanças se tornem possíveis Em especial a coordenação do curso de Arquitetura e Urbanismo pelo apoio e motivação de todos os envolvidos.

\section{Referências}

AIA. AIA Digital Practice Guide and Samples. Disponível em: <http://www.aia.org/contractdocs/AIAB095713> Acesso em: 21 jun. 2015.

ABNT - Associação Brasileira de Normas Técnicas. NBR 13.532 - Elaboração de projetos de edificações - Arquitetura. Rio de Janeiro, 1995.

Barham, W., Meadati, P.; Irizarry. Enhancing student learning in structures courses with building information modeling. Congress on Computing in Civil Engineering, 2011 () p. 850-857 SCOPUS (Elsevier).

Barison, M. B.; Santos, E. T. Ensino de BIM: tendências atuais no cenário Internacional. Gestão \& Tecnologia de Projetos, São Carlos, v. 6, n. 2, p. 67-80, dez. 2011. Disponível em: <http://www.iau.usp.br/posgrad/gestaodeprojetos/index. php/gestaodeprojetos/article/view/218>. Acesso em 11 jan. 2013.

Denzer A.S. and Hedges K.E. (2008). From CAD to BIM: educational strategies for the coming paradigm shift. Proceedings of the 2008 Architectural Engineering National Conference (Ettouney M., editor), The Architectural Engineering Institute (AEI) of the ASCE, September 24-27, Denver, Colorado, USA. Disponível em:<http://ascelibrary. org/doi/pdf/10.1061/41002\%28328\%296>. Acesso em 10 jan. 2012.

Delatorre, Vivian. Potencialidades e limites do BIM no ensino de Arquitetura: Uma proposta de implementação; Orientadora, Alice Teresinha Cybis Pereira. Dissertação. Universidade Federal de Santa Catarina, Florianópolis, SC, 2014. 293p.

Delatorre, V.; Pereira, A. T. C.; Pupo, R. T.. The teaching of architectural drawing using BIM (Building Information Modeling): Concepts and tools. In: 3rd. International Conference on Integration of Design, Enginnering and Management for innovation, 2013, Porto. PROCEEDINGS OF 3rd International Conference on Integration of Design, Engineering and Management for innovation, 2013. p. 543552.

Eastman, Chuck; Teicholz, Paul; Sacks, rafael; Liston, Kathleen. Manual de BIM: Um guia de modelagem da informação da construção para arquitetos, engenheiros, gerentes, construtores e incorporadores. Porto Alegre: 
Bookman, 2014.

Kiviniemi, Arto. Challenges and opportunities in the BIM education How to include BIM in the future curricula of AEC professionals?. 2013. Disponível em: <http://www. nibs.org/?page=conference_bim>. Acesso em: 20 mar. 2015. Kowaltowski, Doris Catharine Cornelie Knatz et al. O processo de projeto em arquitetura: da teoria à tecnologia. São Paulo: Oficina de Textos, 2011, 504p.

Lawson, Bryan. Como os arquitetos e designers pensam. Tradução Maria Beatriz Medina. São Paulo: Oficina de Textos, 2011.

Neves, Laerte Pedreira. Adoção do Partido na Arquitetura. Salvador. Editora da Universidade Federal da Bahia, 1998.

Oxman, R. Theory and design in the first digital age. Design Studies (2006). Disponível em: <http://www.technion. ac.il/ rivkao/topics/publications/Oxman_2006_DesignStudies.pdf $>$. Acesso em 30 abr. 2015

Ruschel; Andrade; Morais. O ensino de BIM no Brasil: onde estamos? Ambiente Construído. Ambient. constr. vol.13 no.2 Porto Alegre Apr./June 2013. Disponível em: <http:// dx.doi.org/10.1590/S1678-86212013000200012>. Acesso em: 15 mar. 2015.

Sacks, R.; Barak, R. (2010). Teaching Building Information Modeling as an Integral Part of Freshman Year Civil Engineering Education. ASCE Journal of Professional Issues in Engineering Education and Practice, Vol. 136 No. 1 pp. 30-38.

Silva, Elvan. Uma introdução ao projeto arquitetônico. 2. ed. rev. e ampl. Porto Alegre: Universidade Federal do Rio Grande do Sul, 2006

Succar, b. Building information modeling framework: a research and delivery foundation for industry stakeholders. Automation in Construction, v. 18, n. 3, p. 357-375, 2008. Disponível em: <www.elsevier.com/locate/autcon>. Acesso em: 15 mar. 2015.

Taylor, J.M.,Liu,J.; HEIN ,M.F.(2008). Integration of Building Information Modeling into an ACCE Accredit construction management curriculum. 44th - ASC Annual International Conference, Associated Schools of Construction, Auburn, AL. 2008 Disponível em: <http://ascpro0.ascweb.org/ archives/cd/2008/paper/CEUE246002008.pdf>. Acesso em 10 abr. 2015. 